\title{
Animal Elements on Japanese Kotowaza and the Implementation of Japanese Socio-Cultural Values \\ A Cognitive Linguistics Point of View
}

\author{
Siti Mafrukha ${ }^{1}$, Dian Bayu Firmansyah ${ }^{2}$, Anggita Stovia ${ }^{3}$ \\ Universitas Jenderal Soedirman, Purwokerto, Jawa Tengah, Indonesia \\ Universitas Jenderal Soedirman, Purwokerto, Jawa Tengah, Indonesia \\ Universitas Jenderal Soedirman, Purwokerto, Jawa Tengah, Indonesia
}

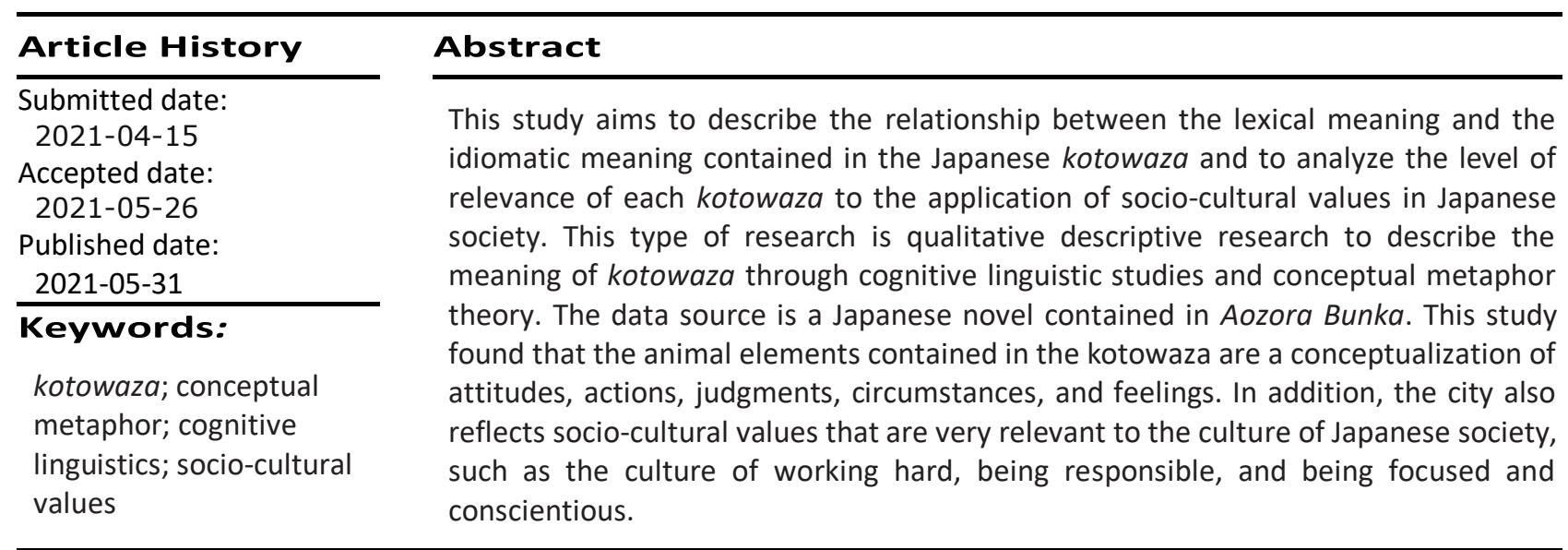

\section{Kata Kunci:}

kotowaza; metafora konseptual; linguistik kognitif; nilai sosial budaya

\section{Abstrak}

Unsur hewan dalam Kotowaza Bahasa Jepang dan Penerapan Nilai Sosial Budaya Masyarakat Jepang: Tinjauan Linguistik Kognitif

Penelitian ini bertujuan untuk mendeskripsikan hubungan antara makna leksikal dan makna idiomatikal yang terdapat pada kotowaza bahasa Jepang, serta menganalisis tingkat relevansi dari tiap-tiap kotowaza, terhadap penerapan nilai-nilai sosial budaya pada masyarakat Jepang. Jenis penelitian yang digunakan adalah penelitian deskriptif kualitatif, untuk mendeskripsikan makna kotowaza melalui kajian linguistik kognitif dan teori metafora konseptual. Sumber data berupa novel Jepang yang terdapat dalam Aozora bunka. Penelitian ini menemukan unsur hewan yang terdapat dalam kotowaza merupakan konseptualisasi dari sikap, tindakan, penilaian, keadaan, dan perasaan. Selain itu, kotowaza tersebut juga mencerminkan nilai sosial budaya yang sangat relevan dengan budaya masyarakat Jepang, seperti budaya bekerja keras, bertanggung jawab, serta fokus dan teliti.

Corresponding author:

${ }^{1}$ mafrukha.s@gmail.com

2 dbayuf@unsoed.ac.id

3 anggita.stovia@unsoed.ac.id 


\section{Pendahuluan}

Peribahasa dalam bahasa Jepang dikenal dengan istilah kotowaza「諺」.Kotowaza merupakan kalimat atau frasa pendek yang umumnya berisi tentang nasihat, kritik, serta sindiran dalam kehidupan manusia, yang disebarluaskan melalui adat istiadat masyarakat setempat (Shinmura, 1973, p. 989). Kotowaza lahir berdasarkan pengamatan dan pengalaman manusia atas peristiwa atau kejadian-kejadian yang berulang, sehingga dapat dijadikan pembelajaran. Makna kotowaza umumnya dikaji berdasarkan kaitan antar maknanya, yaitu dengan menjelaskan hubungan antara makna leksikal dan makna kiasannya (Yohani, 2015). Namun, dalam kamus kotowaza, biasanya penjelasan yang ada hanya memuat makna leksikal serta kiasannya saja tanpa adanya penjelasan yang lebih rinci.

Linguistik kognitif merupakan salah satu cabang linguistik yang menekankan pada berbagai hubungan dalam bahasa, yang mewakili informasi dalam otak manusia. Linguistik kognitif muncul pada tahun 1980-an. Tokoh aliran ini adalah George Lakoff, Mark Johnson, Ronald W Langacker. Kognitif yang dimaksud dalam aliran ini yaitu seluruh kegiatan pikiran manusia dalam memahami dan memaknai setiap pengalaman barunya secara subjektif dalam mengatur berbagai informasi yang diperoleh dengan tepat.

Melalui karyanya yang fenomenal, Lakoff dan Johnson (1980), menyatakan bahwa metafora telah meresap dalam kehidupan sehari-hari, tidak hanya dalam bahasa tetapi juga dalam pikiran dan tindakan. Sistem konseptual manusia pada dasarnya bersifat metaforis. Ini berarti bahwa struktur kognitif manusia dapat dilihat melalui metafora yang terwujud dalam bahasa.

Metafora (隠喻" in-yu") digunakan untuk mengumpamakan sesuatu hal (misalnya A) dengan hal yang lain (misalnya B), karena adanya kemiripan atau kesamaan (Momiyama, 2010, p. 35). Croft menyatakan pula bahwa konsep domain metafora adalah adanya kesamaan dari domain asal ke domain target (Geeraerts, 2006, p. 278). Domain yang dimaksud adalah makna yang mengandung polisemi. Contohnya kalimat 君は僕の太陽だ Kimi wa boku no taiyouda 'Kau adalah matahariku'. Matahari dalam kata tersebut diasumsikan sebagai seorang kekasih. Persamaan atau kemiripan matahari dengan kekasih adalah karena peran vital matahari sebagai sumber energi yang sangat dibutuhkan dalam kehidupan manusia. Oleh karena itu dalam perumpamaan tersebut 'kekasih' dianalogikan dengan 'matahari' karena dianggap memiliki kedudukan yang sama vital seperti matahari, yaitu sebagai sumber energi dan sumber inspirasi yang sangat diperlukan dalam kehidupan seseorang.

Sebelumnya, penelitian kotowaza dalam ranah semantik telah dilakukan oleh Santoso dan Riani (2019) serta Hanindar dan Andini (2017). Kemudian, ada pula penelitian Hadi (2018) serta Kharina dan Sudjianto (2016) dalam penelitiannya, kotowaza dianalisis hanya berdasarkan budayanya saja. Lalu, penelitian kotowaza dan kanyouku 'idiom' dalam ranah linguistik kognitif pernah dilakukan Sekarsari dan Haristiani (2016) serta Yohani (2015) namun dalam penelitiannya kurang memberikan penjelasan lebih rinci mengenai hubungan kotowaza dengan budaya yang dimaksud. Penelitian lain terkait metafora konseptual juga dilakukan oleh Ghassani dan Saifudin (2020) (2018), serta Swasono (2013) dengan data berupa idiom bahasa Jepang. Dapat disimpulkan bahwa umumnya penelitian kotowaza, dilakukan menggunakan kajian di luar kajian linguistik kognitif. Sehingga, berbeda dengan penelitian sebelumnya, penelitian ini menganalisis hubungan antara makna leksikal dan makna idiomatikal kotowaza yang mengandung unsur hewan berdasarkan kajian linguistik kognitif, serta memaparkan relevansi kotowaza tersebut dengan nilai sosial budaya Jepang yang tercermin pada masyarakat Jepang. Pemilihan unsur hewan dalam penelitian ini dilakukan karena kotowaza bahasa Jepang yang menggunakan unsur hewan cukup banyak ditemui dan menarik untuk ditelusuri sejauh 
mana korelasi antara hewan-hewan tersebut dengan kondisi sosial budaya Jepang.

\section{Metode Penelitian}

Metode yang digunakan dalam penelitian ini adalah deskriptif kualitatif. Objek penelitian ini dibatasi pada 30 data kotowaza yang mengandung unsur hewan. Sumber data yang digunakan dalam penelitian ini yaitu novel-novel Jepang yang diakses pada Aozora Bunko (https://www.aozora.gr.jp/). Dengan demikian, peneliti mengasumsikan keseluruhan objek penelitian ini merupakan jitsurei atau contoh penggunaan kalimat asli dalam novel, dan objek penelitian ini layak untuk diteliti.

Teknik yang digunakan dalam pengumpulan data penelitian ini adalah teknik pustaka dan teknik catat. Teknik pustaka berkaitan dengan kajian teoretis dan referensi lain terkait dengan nilai, budaya dan norma yang berkembang pada situasi sosial yang diteliti (Sugiyono, 2013, p. 291). Teknik lanjutan berupa teknik catat. Teknik catat yang digunakan dalam penelitian ini yaitu mencatat peribahasa Jepang yang mengandung unsur hewan yang relevan dengan data penelitian ini yang telah didapat dari kutipan novel Jepang (daring).

Pada penelitian ini, metode deskriptif dengan penyajian informal digunakan untuk menganalisis peribahasa Jepang dari sudut pandang kajian linguistik kognitif. Metode penyajian informal adalah perumusan dengan kata-kata biasa (Sudaryanto, 2015, p. 145). Analisis dilakukan dengan mengkaji makna leksikal dan idiomatikal kotowaza dengan menelaah kamus sesuai dengan teori makna (Chaer, 2009). Kemudian dianalisis metafora hewan dengan menggunakan metafora konseptual Lakoff dan Johnson (1980). Pada tahap ini dilakukan proses pemetaan masing-masing kotowaza, untuk mengetahui apa yang menjadi latar belakang dari suatu peristiwa yang terjadi, sehingga dapat diekspresikan menggunakan kotowaza dengan unsur hewan tersebut. Setelah itu, dilakukan penarikan kesimpulan yang membahas relevansi unsur kotowaza yang ada, dengan penerapan nilai sosial budaya masyarakat Jepang. Penarikan kesimpulan dilakukan dengan menjabarkan data dan fakta yang ada, dengan mengacu pada penelitian yang dilakukan oleh (Trahutami, 2015) serta (Seng, 2007).

\section{Hasil dan Pembahasan}

\subsection{Hasil}

Berikut ini disajikan tabel 1 yang memuat data keseluruhan hasil temuan penelitian, yang telah dikelompokkan berdasarkan relevansi makna kotowaza terhadap nilai sosial budaya Jepang. Seperti yang telah dijelaskan pada bagian sebelumnya, proses analisis data tabel 1 tersebut disajikan dengan cara mengambil beberapa buah contoh data berdasarkan kategori nilai sosial budaya. Ada 2 (dua) tingkatan analisis data yang dilakukan yaitu: 1) menganalisis hubungan antara makna leksikal dan makna idiomatikal dari kotowaza yang mengandung unsur hewan melalui teori metafora konseptual, 2) melakukan analisis terhadap kotowaza yang mengandung unsur hewan secara mendalam untuk mengetahui ada atau tidaknya relevansi antara kotowaza tersebut dengan unsur sosial budaya masyarakat Jepang berdasarkan perspektif linguistik kognitif. Selanjutnya dibagian terakhir disajikan pembahasan dari keseluruhan hasil analisis data yang telah dilakukan.

Dari 30 buah data yang ditemukan, dilakukan analisis secara mendalam pada 6 (enam) buah data yang dianggap mewakili keseluruhan data yang ada, dan sisanya sebanyak 24 buah data yang ditemukan disajikan pada tabel ringkasan data hasil penelitian berikut, untuk memperlihatkan relevansi dari tiap-tiap kotowaza dengan nilai sosial budaya Jepang. 
Mafrukha, S., Firmansyah, D.B., Stovia, A., (2021). Animal Elements on Japanese Kotowaza and the Implementation of Japanese Socio-Cultural Values: A Cognitive Linguistics Point of View. Japanese Research on Linguistics, Literature, and Culture 3 (2), 141-156. https://doi.org/10.33633/jr.v3i2.4599

Tabel 1. Relevansi Kotowaza dan Nilai Sosial Budaya Jepang

\begin{tabular}{|c|c|c|c|c|}
\hline No & Data Kotowaza & Kalimat & Makna Kotowaza & Nilai Sosial Budaya \\
\hline 1. & 馬車馬のように & $\begin{array}{l}\text { 例えばバルザックやドストエフスキーの } \\
\text { ような作家にあっては、時として馬車馬 } \\
\text { のように駆り立てられ、ただ書かんがた } \\
\text { めに筆を走らせたような点さえ見受けら } \\
\text { れる。 }\end{array}$ & $\begin{array}{l}\text { Nasihat bekerja } \\
\text { keras }\end{array}$ & $\begin{array}{l}\text { Usaha Keras dan } \\
\text { Pantang Menyerah }\end{array}$ \\
\hline 2. & エビで鯛を釣る & $\begin{array}{l}\text { ・・人が京弥のすばらしい女装姿に見 } \\
\text { 惚れて通ったならば、いつかそのあでや } \\
\text { か振りが伝わって、百化け十吉の耳にも } \\
\text { 這入り、或は直接また目にもかけ、うま } \\
\text { うま海老で鯛を釣る事が出来るだろうと } \\
\text { 思ったからでした。 }\end{array}$ & $\begin{array}{l}\text { Berusaha } \\
\text { mencapai tujuan } \\
\text { dengan memakai } \\
\text { akal yang cerdik }\end{array}$ & $\begin{array}{l}\text { Usaha Keras dan } \\
\text { Pantang Menyerah }\end{array}$ \\
\hline 3. & $\begin{array}{l}\text { 井の中の蛙大海を } \\
\text { 知らず }\end{array}$ & $\begin{array}{l}\text { ある大学系の病院で三年一問働いたあ } \\
\text { と、別の病院で働くという時代が必ずく } \\
\text { る。そうすることによって自分の能力一 } \\
\text { を上げ、患者さんのための本当の意味で } \\
\text { のいい医者になれる力をつけられると私 } \\
\text { は思います。*井の中の蛙大海を知らず。 }\end{array}$ & $\begin{array}{l}\text { Sikap untuk } \\
\text { bersabar dan } \\
\text { bekerja keras } \\
\text { mengembangkan } \\
\text { potensi diri }\end{array}$ & $\begin{array}{l}\text { Usaha Keras dan } \\
\text { Pantang Menyerah }\end{array}$ \\
\hline 4. & 亀の甲より年の功 & 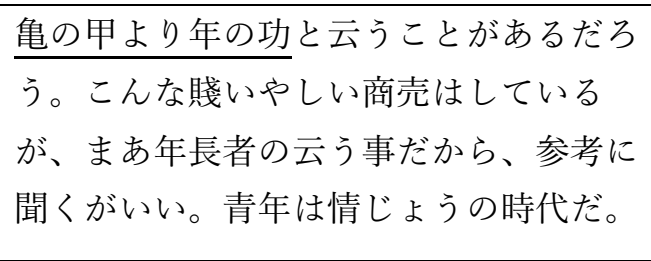 & $\begin{array}{l}\text { Nasihat pantang } \\
\frac{\text { menyerah }}{\text { mencapai }} \\
\frac{\text { kesuksesan walau }}{\text { tidak sesuai }} \\
\text { keinginan }\end{array}$ & $\begin{array}{l}\text { Usaha Keras dan } \\
\text { Pantang Menyerah }\end{array}$ \\
\hline 5. & 鶏群の一鶴 & $\begin{array}{l}\text { お雪はあの土地の女には似合わしからぬ } \\
\text { 容色と才智とを持っていた。鷄群の一鶴 } \\
\text { であった。 }\end{array}$ & $\begin{array}{l}\text { Sikap bekerja } \\
\text { keras dan } \\
\text { pantang } \\
\text { menyerah walau } \\
\text { berbeda dengan } \\
\text { yang lain }\end{array}$ & $\begin{array}{l}\text { Usaha Keras dan } \\
\text { Pantang Menyerah }\end{array}$ \\
\hline 6. & 鯉の滝登り & $\begin{array}{l}\text { とにかく、家康は後運の人だった。初 } \\
\text { 年、惨備。中年、不運。そして、晚年に } \\
\text { きて一気に鯉の滝登りのような上昇 } \\
\text { 運。・・・「重き荷を負うて遠き道を行 } \\
\text { くが如しーー」と。 }\end{array}$ & $\begin{array}{l}\text { Nasihat pantang } \\
\text { menyerah walau } \\
\text { mengalami } \\
\text { kegagalan } \\
\text { bertubi-tubi }\end{array}$ & $\begin{array}{l}\text { Usaha Keras dan } \\
\text { Pantang Menyerah }\end{array}$ \\
\hline 7. & $\begin{array}{l}\text { 虎穴に入らずんば } \\
\text { 虎児を得ず }\end{array}$ & $\begin{array}{l}\text { 「虎穴に入らずんば虎児を得ず」といっ } \\
\text { てな。・・・だけど、自分が食べられる } \\
\text { 可能性もあるんだよなところが、聴柄な } \\
\text { 人間が行動したときは、失敗しないよう } \\
\text { に作戦を立ててから行動するから、そっ } \\
\text { ちのほうがよかったりするんだよ。 }\end{array}$ & $\begin{array}{l}\text { Nasihat untuk } \\
\text { berani mengambil } \\
\text { risiko }\end{array}$ & $\begin{array}{l}\text { Usaha Keras dan } \\
\text { Pantang Menyerah }\end{array}$ \\
\hline
\end{tabular}


Mafrukha, S., Firmansyah, D.B., Stovia, A., (2021). Animal Elements on Japanese Kotowaza and the Implementation of Japanese Socio-Cultural Values: A Cognitive Linguistics Point of View. Japanese Research on Linguistics, Literature, and Culture 3 (2), 141-156. https://doi.org/10.33633/jr.v3i2.4599

\begin{tabular}{llll}
\hline \hline 8. 猿も木から落ちる & 老弁護士の無念さがよく理解でき & Nasihat agar tidak & Usaha Keras dan \\
& た。・・・「猿も木から落ちると言うじ & mudah putus asa & Pantang Menyerah \\
& やありませんか？ 苦になさらないほう & \\
& がいいですわ」彼女は、爺さんを慰め \\
& た。
\end{tabular}

\begin{tabular}{|c|c|c|}
\hline \multirow[t]{3}{*}{9.} & 鳩に三枝の礼あ & 「鳩に三枝の礼あり、烏に反哺の孝あ \\
\hline & り、烏に反哺の孝 & り」について、・・・烏と鳩とに比べら \\
\hline & あり & $\begin{array}{l}\text { るるのは吾人の耻である。吾人は自覚あ } \\
\text { る「人」として孝たるを欲す。愛なき孝 } \\
\text { は冷たき虚礼に過ぎぬ。 }\end{array}$ \\
\hline
\end{tabular}

10. 犬は三日飼えば三 飼主の人間どもが転居する時・・・旧家
年恩を忘れないに住み続けたがる。だから、三日飼われ てその恩を三年忘れない犬と反対に、猫 Sikap bakti Balas Budi kepada orang tua は三年飼われてその恩を三日にして忘れ る。

\begin{tabular}{|c|c|c|c|c|}
\hline 11. & 魚心あれば水心 & $\begin{array}{l}\text { 林は一年中つづけて、長篇を書いたほか } \\
\text { 月々三つも四つも短篇を書いた。・・・ } \\
\text { こんな無理を強いたのはジャーナリズム } \\
\text { だったと、平林はいうのである。林がこ } \\
\text { れは魚心と水心だっと思もっている。 }\end{array}$ & $\begin{array}{l}\text { Ajaran memberi } \\
\text { agar menerima } \\
\text { kebaikan }\end{array}$ & Balas Budi \\
\hline 12. & $\begin{array}{l}\text { キジも鳴かずば撃 } \\
\text { たれまい }\end{array}$ & $\begin{array}{l}\text { ・・・もっと危険なのは、だまっていれ } \\
\text { ばことを起こさないですむものを、いら } \\
\text { ないことまで口走るから、「キジも鳴か } \\
\text { ずば撃たれまい」という結果を招く。 }\end{array}$ & $\begin{array}{l}\text { Nasihat untuk } \\
\text { mempertanggung } \\
\text { jawabkan ucapan }\end{array}$ & $\begin{array}{l}\text { Bertanggungjawab } \\
\text { dan malu }\end{array}$ \\
\hline 13. & $\begin{array}{l}\text { 猫の目ように変わ } \\
\text { る }\end{array}$ & $\begin{array}{l}\text { ・・建武元年八月のことである。現今 } \\
\text { でいう裁判所の裁判官であった。猫の目 } \\
\text { ように変わる。所領問題などをめぐる訴 } \\
\text { 訟を裁定する職務である。 }\end{array}$ & $\begin{array}{l}\text { Sikap ber- } \\
\text { tanggungjawab } \\
\text { dengan pekerjaan } \\
\text { walau berubah } \\
\text { dengan cepat }\end{array}$ & $\begin{array}{l}\text { Bertanggungjawab } \\
\text { dan malu }\end{array}$ \\
\hline 14. & 猫をかぶっている & $\begin{array}{l}\text { 何故なら親たちと一緒に正一が洋楽を好 } \\
\text { かないの・・・少し意地わるく、若しか } \\
\text { したらわざと猫をかぶっているのかしら } \\
\text { とも思わないでもなかった。兵隊に行っ } \\
\text { ていて、その二年間は都会の空気の中で } \\
\text { 暮して来た正一が、ジャズなんか好きに } \\
\text { なってかえったとしれると思った。 }\end{array}$ & Sikap pemalu & $\begin{array}{l}\text { Bertanggungjawab } \\
\text { dan malu }\end{array}$ \\
\hline 15. & 鷹も朋輩犬も朋輩 & $\begin{array}{l}\text { うちの会社の社訓は、鷹も朋輩犬も朋輩 } \\
\text { で、部署や役職の隔たりを越えて一丸と } \\
\text { なってプロジェクトを進めるから業績が } \\
\text { 伸びていると思うよ。 }\end{array}$ & $\begin{array}{l}\text { Nasihat untuk } \\
\text { bertanggung } \\
\text { jawab sebagai } \\
\text { rekan kerja }\end{array}$ & $\begin{array}{l}\text { Bertanggung jawab } \\
\text { dan malu }\end{array}$ \\
\hline
\end{tabular}


Mafrukha, S., Firmansyah, D.B., Stovia, A., (2021). Animal Elements on Japanese Kotowaza and the Implementation of Japanese Socio-Cultural Values: A Cognitive Linguistics Point of View. Japanese Research on Linguistics, Literature, and Culture 3 (2), 141-156. https://doi.org/10.33633/jr.v3i2.4599

\begin{tabular}{|c|c|c|c|c|}
\hline 16. & 鳥無き里の蝙蝠 & $\begin{array}{l}\text { ・・しかし一生懸命に教えている中 } \\
\text { に、半年程経つと、お弟子も大分来てく } \\
\text { れるようになり、私は㡺間は筝を教え } \\
\text { て、夜は鳥なき里のこうもりょうにとで } \\
\text { も言おうか、私の下手な尺八をおじさん } \\
\text { 達に教えていた。 }\end{array}$ & $\begin{array}{l}\text { Nasihat agar tak } \\
\text { sombong dengan } \\
\text { kemampuan diri }\end{array}$ & $\begin{array}{l}\text { Bertanggungjawab } \\
\text { dan malu }\end{array}$ \\
\hline 17. & $\begin{array}{l}\text { 飢えたる犬は棒を } \\
\text { 恐れず }\end{array}$ & $\begin{array}{l}\text { 早春のこと。夕食の少しまえに、その老 } \\
\text { 人はすぐ近くの商店へ行くである。飢え } \\
\text { たる犬は棒を恐れずだからと言って、商 } \\
\text { 店で強盗をしてもすぐに捕まるよ。 }\end{array}$ & $\begin{array}{l}\text { Ajaran } \\
\text { bertanggung } \\
\text { jawab atas } \\
\text { tindakan yang } \\
\text { dilakukan }\end{array}$ & $\begin{array}{l}\text { Bertanggungjawab } \\
\text { dan malu }\end{array}$ \\
\hline 18. & 馬の耳に念仏さ & $\begin{array}{l}\text { 要するに学長の私物を図書館の予算から } \\
\text { 購入するための隠れ蓑なんだよ。さすが } \\
\text { に理事会から改善を勧告されているんだ } \\
\text { が、学長には馬の耳に念仏さ。 }\end{array}$ & $\begin{array}{l}\text { Sikap agar } \\
\text { menjadi orang } \\
\text { yang mau } \\
\text { dinasihati }\end{array}$ & $\begin{array}{l}\text { Bertanggungjawab } \\
\text { dan malu }\end{array}$ \\
\hline 19. & $\begin{array}{l}\text { 犬もあるけば棒に } \\
\text { あたる }\end{array}$ & $\begin{array}{l}\text { ・・・親分の吉五郎は金杉の浜で鯨をつ } \\
\text { かまえたほどに驚いた。「犬もあるけば } \\
\text { 棒にあたると言うが、手前もうろうろし } \\
\text { ているうちに、ど偉いことをしやがった } \\
\text { な。」 }\end{array}$ & $\begin{array}{l}\text { Mendapat } \\
\text { keberuntungan } \\
\text { karena fokus } \\
\text { terhadap hal yang } \\
\text { dilakukan }\end{array}$ & $\begin{array}{l}\text { Sikap fokus dan } \\
\text { teliti }\end{array}$ \\
\hline 20. & 胡蝶の夢 & $\begin{array}{l}\text { 夢の中で蝶になっていた男が、目覚めた } \\
\text { 後に、「この私は、蝶になった夢を見て } \\
\text { いた人間なのか。・・・この「胡蝶の } \\
\text { 夢」の逸話を思い出す。たとえ゙「幸せ } \\
\text { とは何か」という問題について語る時、 } \\
\text { このように言う人がよくいる。「自分が } \\
\text { 幸せだと思っていれば、それが幸せなん } \\
\text { ですよ」 }\end{array}$ & $\begin{array}{l}\text { Nasihat agar } \\
\text { fokus dan teliti } \\
\text { terhadap } \\
\text { pemikiran sendiri }\end{array}$ & $\begin{array}{l}\text { Sikap fokus dan } \\
\text { teliti }\end{array}$ \\
\hline 21. & $\begin{array}{l}\text { 二鬼を追う者は一 } \\
\text { 兔を得 }\end{array}$ & $\begin{array}{l}\text { 静「だからサ。本当は士官に成る気なん } \\
\text { だけども、もし身体が悪くッてなれなか } \\
\text { った、動物学者にも成るのサ。」文、 } \\
\text { そんなに両天称を掛けたッていけるもん } \\
\text { か。二鬼を追う者は一兔を得ずッてェ事 } \\
\text { がある。どっちか一方ひとつに極きめた } \\
\text { まい!」 }\end{array}$ & $\begin{array}{l}\text { Nasihat untuk } \\
\text { fokus pada satu } \\
\text { hal utama dan } \\
\text { jangan rakus }\end{array}$ & $\begin{array}{l}\text { Sikap fokus dan } \\
\text { teliti }\end{array}$ \\
\hline 22. & 頭の黒い鼠 & $\begin{array}{l}\text { ・・・頭の黒い鼠どもと同居では隠居は } \\
\text { とても寝つかれませんし、あらぬ疑いを } \\
\text { かけられた一同は気持よく正月も迎えら } \\
\text { れません。 }\end{array}$ & $\begin{array}{l}\text { Nasihat supaya } \\
\text { waspada } \\
\text { terhadap pencuri }\end{array}$ & $\begin{array}{l}\text { Kewaspadaan } \\
\text { hidup }\end{array}$ \\
\hline 23. & $\begin{array}{l}\text { 蜂の巣つついたよ } \\
\text { うな }\end{array}$ & $\begin{array}{l}\text { もう一度や二度、よび出しがあるかも知 } \\
\text { れませんね今夜は、先生の顔立てておと }\end{array}$ & $\begin{array}{l}\text { Waspada agar tak } \\
\text { membuat } \\
\text { kekacauan }\end{array}$ & $\begin{array}{l}\text { Kewaspadaan } \\
\text { hidup }\end{array}$ \\
\hline
\end{tabular}


Mafrukha, S., Firmansyah, D.B., Stovia, A., (2021). Animal Elements on Japanese Kotowaza and the Implementation of Japanese Socio-Cultural Values: A Cognitive Linguistics Point of View. Japanese Research on Linguistics, Literature, and Culture 3 (2), 141-156. https://doi.org/10.33633/jr.v3i2.4599

\begin{tabular}{|c|c|c|c|c|}
\hline & & $\begin{array}{l}\text { なしくしておりますが、こんどは私が一 } \\
\text { 人で参ります。蜂の巣つついたような論 } \\
\text { 議になればしめたもんです。 }\end{array}$ & & \\
\hline 24. & 杯中の蛇影 & $\begin{array}{l}\text { 杜宣という人物が、友人の家で酒を飲ん } \\
\text { でいたとき、彼は一層疑惑をふかめ、.杯 } \\
\text { 中の蛇影を見るに違いない。そのまま飲 } \\
\text { み続けた彼は、しばらくして病気になっ } \\
\text { てしまいます。 }\end{array}$ & $\begin{array}{l}\text { Sikap berhati-hati } \\
\text { itu perlu, tapi } \\
\text { jangan berlebihan }\end{array}$ & $\begin{array}{l}\text { Kewaspadaan } \\
\text { hidup }\end{array}$ \\
\hline 25. & 蛇に睨まれた蛙 & $\begin{array}{l}\text { 傍目には親しい者同士が楽しく談笑して } \\
\text { いるように見えるが、実際は蛇に睨まれ } \\
\text { た蛙と、蛙をいたぶろうと舌なめずりし } \\
\text { ている蛇のようなものだルイーゼは渋々 } \\
\text { ながら、事情を話す。からかわれるので } \\
\text { はないか、笑われるのではないかと思っ } \\
\text { たが、意外なことにマティアスは最後ま } \\
\text { で黙って聞いた。 }\end{array}$ & $\begin{array}{l}\text { Jangan } \\
\text { mengintimidasi } \\
\text { orang }\end{array}$ & $\begin{array}{l}\text { Kewaspadaan } \\
\text { hidup }\end{array}$ \\
\hline 26. & $\begin{array}{l}\text { 飼い犬に手を噛ま } \\
\text { れる }\end{array}$ & 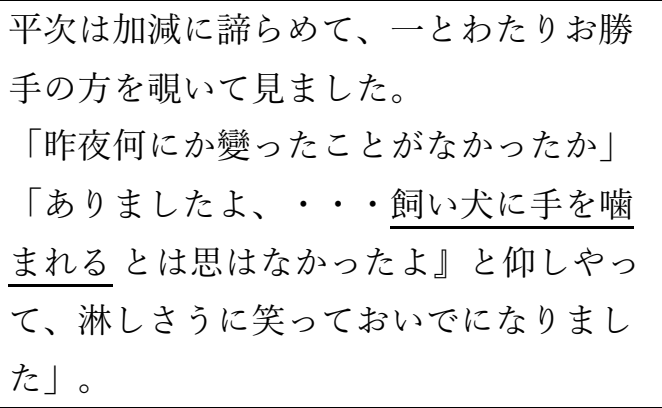 & $\begin{array}{l}\text { Dikhianati oleh } \\
\text { orang yang } \\
\text { dipercaya }\end{array}$ & $\begin{array}{l}\text { Kewaspadaan } \\
\text { hidup }\end{array}$ \\
\hline 27. & 泣き面に蜂ように & $\begin{array}{l}\text { 鼠が牧畜に必要な草や人間大事の穀物を } \\
\text { 損ずるは夥しいものあり。ロナ島へどこ } \\
\text { からとも知れず鼠群れ来って島中の穀を } \\
\text { 食い尽した上、泣き面に蜂ようにとか、 } \\
\text { 水夫が上陸してただ一正あった牛を掠め } \\
\text { 去ったから、全く食物なくなったのに一 } \\
\text { 年間来らず、全島の民が死に尽した。 }\end{array}$ & $\begin{array}{l}\text { Berhati-hati agar } \\
\text { tak mendapat } \\
\text { kemalangan } \\
\text { bertubi-tubi }\end{array}$ & $\begin{array}{l}\text { Kewaspadaan } \\
\text { hidup }\end{array}$ \\
\hline 28. & $\begin{array}{l}\text { 猫の首に鈴をつけ } \\
\text { れば }\end{array}$ & $\begin{array}{l}\text { あるとき、ネズミたちが集まって、どう } \\
\text { やったら猫に狙われる危険から逃れられ } \\
\text { るか、相談をしました。あるネズミが、 } \\
\text { 猫の首に鈴をつければ近づいてくればす } \\
\text { ぐにわかる・・・しかし、年寄りのネズ } \\
\text { ミが「だが、だれが猫に鈴を付けるんだ } \\
\text { ね」と言うと、みんな㷛り込んでしまっ } \\
\text { たということです。 }\end{array}$ & $\begin{array}{l}\text { Nasihat untuk } \\
\text { selalu waspada } \\
\text { terhadap situasi } \\
\text { apapun }\end{array}$ & $\begin{array}{l}\text { Kewaspadaan } \\
\text { hidup }\end{array}$ \\
\hline 29 & $\begin{array}{l}\text { 角を矯めて牛を殺 } \\
\text { す }\end{array}$ & $\begin{array}{l}\text { 迷うことはよいとしても、迷いに迷った } \\
\text { あげく、自分というものを見失なってし }\end{array}$ & $\begin{array}{l}\text { Sikap berhati-hati } \\
\text { dalam } \\
\text { memperbaiki }\end{array}$ & $\begin{array}{l}\text { Kewaspadaan } \\
\text { hidup }\end{array}$ \\
\hline
\end{tabular}




\begin{tabular}{|c|c|c|c|}
\hline & $\begin{array}{l}\text { まっては、俗にいう“角を矯めて牛を殺す” } \\
\text { ことになってしまうでしょう。 }\end{array}$ & $\begin{array}{l}\text { sesuatu jangan } \\
\text { sampai malah } \\
\text { merusak } \\
\text { segalanya }\end{array}$ & \\
\hline 30. $\quad$ 鶴の一声 & $\begin{array}{l}\text { トップに立つ人にとっては、「鶴の一 } \\
\text { 声」を発するのは、気持ちのいいこと } \\
\text { で、自分のパワーを実感できます。その } \\
\text { 実感をもとに、自分の賢明さとか、発想 } \\
\text { 力の強さとか、自分自身の慎重さという } \\
\text { ようなものを感じることができます。 }\end{array}$ & $\begin{array}{l}\text { Nasihat agar tak } \\
\text { menjadi orang } \\
\text { serakah karena } \\
\text { memiliki otoritas } \\
\text { kuat }\end{array}$ & $\begin{array}{l}\text { Kewaspadaan } \\
\text { hidup }\end{array}$ \\
\hline
\end{tabular}

\subsection{Hubungan Makna Leksikal dan Makna Idiomatikal Kotowaza Bahasa Jepang yang Mengandung Unsur Hewan}

Hubungan antara makna leksikal dan makna idiomatikal dari kotowaza Bahasa Jepang yang mengandung unsur hewan, berikut ini dijabarkan dengan menampilkan hasil analisis dari 6 (enam) buah data yang ditemukan dan dianggap mewakili dari jumlah 30 data yang ada pada tabel 1.

\section{Data 1}

頭の黒いネズミ

\section{Atama no kuroi nezumi}

Pada data 1 di atas memiliki makna leksikal 'tikus berkepala hitam' sedangkan makna idiomatikalnya adalah 'penjahat atau pencuri'. Berdasarkan analisis metafora konseptual hubungan makna leksikal dan idiomatikalnya ditunjukkan berdasarkan analogi antara sifat tikus hitam yang suka mencuri atau merusak makanan dan sifat penjahat atau pencuri. Tikus pencuri pada umumnya berwarna hitam dan kotor, bukan tikus putih yang berkonotasi bersih. Penggunaan kepala dalam idiom ini untuk menegaskan kejengkelan orang terhadap perilaku tikus hitam yang menyusahkan orang. Kepala merepresentasikan otak yang mengatur perilaku tikus ataupun orang. Dalam hal ini, kotowaza atama no kuroi nezumi juga melibatkan metonimi, yakni representasi kepala untuk tikus hitam.

Berikut ini terlampir kutipan lengkap isi cerita novel bahasa Jepang yang memuat kotowaza pada data 1 di atas.

$$
\begin{gathered}
\text { 煤はらいもすみ、お風吕も落して正月を待つばかりですが、思いをかけた銀包みがせっ } \\
\text { かく現れても、頭の黒い鼠どもと同居では隠居はとても葠つかれませんし、あらぬ疑い } \\
\text { をかけられた一同は気持よく正月も迎えられません。 } \\
\text { (https://www.aozora.gr.jp/cards/001095/files/45936 39308.html) }
\end{gathered}
$$

Susuharai mo sumi, ofuro mo otoshite shōgatsu o matsu bakaridesuga, omoi o kaketa gin tsutsumi ga sekkaku arawarete mo, atama no kuroi nezumi-domo to dōkyo de wa inkyo wa totemo netsukaremasen shi, aranu utagai o kakerareta ichidō wa kimochi yoku shōgatsu mo mukaeraremasen.

'Saya hanya menunggu tahun baru setelah bersih-bersih dan mandi, bahkan jika bungkus perak yang saya pikirkan itu muncul, saya ragu tidak bisa tidur ketika saya tinggal bersama dengan tikus berkepala hitam, dan orang-orang yang merasa curiga juga tidak akan bisa tenang dalam menyambut tahun baru.'

Konteks kalimat pada data 1 di atas, menceritakan perumpamaan pada saat tahun baru di Jepang, ada seseorang yang sedang menunggu waktu tahun baru hanya berada di rumah setelah bersih-bersih dan mandi. Seseorang tersebut ragu tidak bisa tidur karena mungkin akan ada tikus 
berkepala hitam. Seperti pada kutipan kotowaza 頭の黒い鼠 atama no kuroi nezumi 'tikus berkepala hitam', yang berarti pencuri atau penjahat yang mungkin akan datang. Hal ini dikarenakan pada saat tahun baru orang-orang akan sibuk dengan kegiatan mereka sendiri, sehingga pencuri atau penjahat akan lebih mudah melakukan aksi jahatnya. Akibatnya siapa pun menyimpan rasa curiga pada orang yang dianggap sebagai penjahat, tentunya tidak akan merasa tenang dan merasa was-was ketika menghadapi perayaan tahun baru.

\section{Data 2}

馬車馬のように

\section{Basha uma no youni}

Data 2 memiliki makna leksikal 'kereta kuda' sedangkan makna idiomatikalnya yaitu 'bekerja keras'. Berdasarkan hubungan analisis metafora konseptual terhadap data 2, terdapat analogi sifat kerja keras tanpa mengenal lelah kuda dan manusia. Manusia yang bekerja tanpa mengenal lelah disamakan dengan kuda yang kuat menarik kereta. Di dalam kotowaza "basha uma no youni" juga melibatkan metonimi karena analogi yang digunakan adalah kereta kuda, sebenarnya yang kuat bukan keretanya, melainkan kuda yang menarik kereta. Di sini kereta kuda sebenarnya merepresentasikan kuda.

Berikut ini terlampir kutipan lengkap isi cerita novel bahasa Jepang yang memuat kotowaza pada data 2 di atas.

$$
\begin{array}{r}
\text { 例えばバルザックやドストエフスキーのような作家にあっては、時として馬車馬のよう } \\
\text { に駆り立てられ、ただ書かんがために筆を走らせたような点さえ見受けられる。 } \\
\text { (https://www.aozora.gr.jp/cards/000906/files/4253722793.html) }
\end{array}
$$

Tatoeba Baruzakku ya dosutoefusuki no yōna sakka ni atte wa, tokitoshite basha uma no yō ni karitaterare, tada kakanga tame ni fude o hashiraseta yōna ten sae miukerareru.

'Misalnya, penulis seperti Balzac dan Dostoevsky, terkadang dipacu seperti kereta kuda, dan hanya dianggap menggunakan kuasnya untuk menulis saja.'

Pada konteks kalimat data 2 di atas, kutipan kotowaza 馬車馬のように basha uma no you ni, 'seperti kereta kuda', menceritakan perumpamaan seorang penulis zaman dulu seperti Balzac dan Dostoevsky yang harus selalu bekerja keras siang malam dalam menciptakan karya-karyanya, seolah-olah hidupnya hanya digunakan untuk menulis karya sastra.

Berdasarkan uraian analisis data 2, dapat disimpulkan metafora pada kotowaza basha uma no youni memetakan makna kerja keras yang direpresentasikan oleh kuda. Kuda yang menarik kereta membutuhkan tenaga besar disamakan dengan orang yang bekerja dengan keras.

\section{Data 3}

蜂の巣つついたような

hachi no su tsutsuita youna

Pada data 3 mengandung makna leksikal 'seperti menusuk sarang lebah', sedangkan makna idiomatikalnya 'perumpamaan orang yang membuat kekacauan atau keributan'. Berdasarkan analisis metafora konseptual, terdapat analogi antara menusuk sarang lebah dengan membuat kekacauan atau keributan. Sarang lebah biasanya dihuni oleh sekelompok lebah, dan lebah sebenarnya bukan binatang pengganggu, meskipun mempunyai sengat yang ditakuti oleh manusia. Apabila sarang lebah diganggu ataupun dirusak oleh manusia, maka akan segera terjadi keributan karena telah membuat lebah-lebah yang bersarang di situ terusik dan menimbulkan kemarahan lebah, sehingga mereka akan menyerang pengganggu sarangnya. Perumpamaan ini sama maknanya dengan peribahasa "membangunkan Harimau tidur" yakni membuat masalah dengan orang yang akan mengakibatkan masalah besar yang padahal kalau dibiarkan saja tidak akan menimbulkan 
masalah. Representasi unsur hewan lebah dalam kotowaza 3 digunakan untuk menggambarkan orang yang sebenarnya tidak akan mengganggu orang lain jika tidak ada pemicunya.

Berikut ini terlampir kutipan lengkap isi cerita novel bahasa Jepang yang memuat kotowaza pada data 3 di atas.

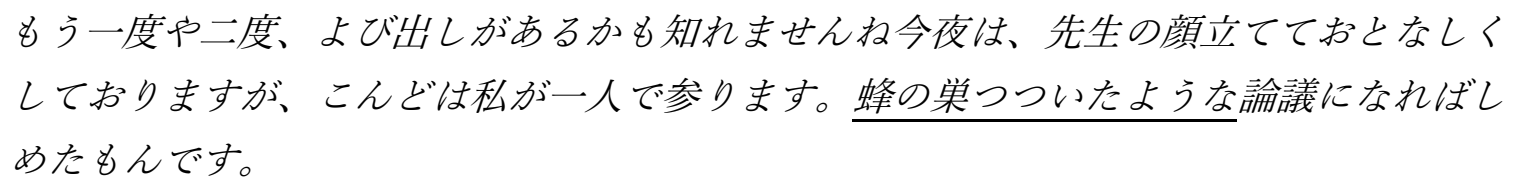

(http://bit.ly/3iM4Kao)

Mōichido ya nido, yobi-dashi ga aru kamo shiremasen ne kon'ya wa, sensei no kao datete otonashiku shite orimasuga, kondo wa watashiga hitori de mairimasu. Hachi no su tsutsuita yōna rongi ni nareba shimeta mondesu.

'Mungkin akan ada panggilan sekali atau dua kali lagi, malam ini, aku diam dengan wajah guru (ekspresi berwibawa), tapi kali ini aku akan datang sendirian. Ini akan menjadi debat seperti menusuk sarang lebah.'

Konteks kalimat pada data 3 di atas, menceritakan seseorang yang akan mengikuti kegiatan debat. Pada kegiatan tersebut dia akan berdebat tanpa partner atau pasangan, sehingga dia berusaha tenang menutupi kekhawatirannya dengan berekspresi 先生の顔立て sensei no kaodate 'wajah guru' atau ekspresi berwibawa. Seseorang tersebut takut jika dalam acara debat tersebut akan ada kekacauan atau keributan, seperti kutipan kotowaza 蜂の巣つついたような hachi no su tsutsuita youna 'seperti menusuk sarang lebah'. Kekhawatiran yang dirasakan seseorang tersebut layaknya akan menusuk sarang lebah atau akan membuat kekacauan dari argumen apa yang dikeluarkannya dari mulutnya nanti saat berdebat. Karena berdasarkan pengalamannya, pendapat yang tidak disetujui dalam forum debat tersebut akan gagal.

\section{Data 4}

鶏群の一鶴

Keigun no ikkaku

Data 4 memiliki makna leksikal 'burung bangau di antara ayam' sedangkan makna idiomatikalnya yaitu 'orang bijak muncul dari kumpulan orang biasa'. Berdasarkan Berdasarkan metafora konseptual, terdapat analogi antara orang bijak yang diumpamakan bangau dan orang biasa yang diumpamakan ayam. Burung bangau dan ayam merupakan hewan yang jenis ungags, namun dari segi bentuknya burung bangau lebih indah dan bernilai dibandingkan ayam. Dalam hal ini bangau dianggap lebih baik dari sekumpulan ayam. Burung bangau yang berbeda sendiri walaupun sesama unggas dengan kumpulan ayam, sebagai perumpamaan orang yang bijak biasanya akan muncul dari kumpulan orang biasa.

Berikut ini terlampir kutipan lengkap isi cerita novel bahasa Jepang, yang memuat kotowaza pada data 4 di atas.

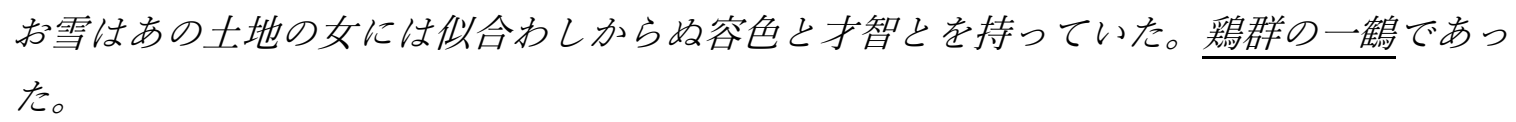

(http://bit.ly/3qfp2fH)

O yuki wa ano tochi no on'na ni wa niawa shikaranu yōshoku to saichi to o motte ita. Keigun no ikkaku deatta.

'Oyuki memiliki kecantikan dan kebijaksanaan yang tidak cocok dengan wanita di negeri itu. Ia adalah burung bangau dari sekawanan ayam.' 
Pada konteks kalimat data 4, diceritakan bahwa ada seorang wanita bernama Oyuki. Oyuki digambarkan sebagai sosok wanita yang berbeda dengan kebanyakan wanita di negeri yang ditinggalinya. Seperti kutipan kotowaza 鶏群の一鶴 keigun no ikkaku 'burung bangau di antara ayam'. Oyuki sebagai perumpamaan layaknya burung bangau di antara sekumpulan ayam atau wanita pada umumnya di negeri tersebut. Hal itu dikarenakan karena sosok Oyuki memiliki kecantikan dan sifat kebijaksanaan yang dianggap tidak cocok di negeri yang ditinggalinya.

\section{Data 5}

泣き面に蜂

\section{Naki tsura ni hachi}

Data 5 memiliki makna leksikal 'seperti lebah di wajah yang menangis', sedangkan makna idiomatikalnya yaitu 'mendapat kemalangan yang bertubi-tubi'. Berdasarkan analisis metafora konseptual, terdapat analogi lebah di wajah yang sedang menangis dengan kemalangan yang bertubi-tubi menimpa seseorang. Orang menangis pada umumnya karena ditimpa kesusahan atau kemalangan, dan dalam keadaan yang susah disengat oleh lebah. Peribahasa ini sama artinya dengan peribahasa dalam bahasa Indonesia "sudah jatuh tertimpa tangga", yang bermakna mendapat kemalangan yang bertubi-tubi.

Berikut ini terlampir kutipan lengkap isi cerita novel bahasa Jepang yang memuat kotowaza pada data 5 di atas.

$$
\begin{aligned}
& \text { 鼠が牧音に必要な草や人間大事の穀物を損ずるは夥しいものあり。口ナ島へどこからと } \\
& \text { も知れず鼠群れ来って島中の穀を食い尽した上、淁き面に蜂ようにとか、水夫が上陸し } \\
& \text { てただ一正あった牛を掠め去ったから、全く食物なくなったのに一年間来らず、全島の } \\
& \text { 民が死に尽した。 }
\end{aligned}
$$

(https://www.aozora.gr.jp/cards/000093/files/4790 35939.html)

Nezumi ga bokuchiku ni hitsuyōna kusa ya ningen daiji no kokumotsu o sonzuru wa obitadashī mono ari. Rona tou e doko karatomo shirezu nezumi mure kitatte shimanaka no koku o kui tsukushita ue, naki tsura ni hachi youni toka, suifu ga jōriku shite tada ippiki atta ushi o kasume satta kara, mattaku shokumotsu nakunatta no ni ichinenkan kitarazu, zentō no min ga shi ni tsukushita.

'Sangat banyak tikus yang merusak rumput dan biji-bijian yang penting bagi manusia untuk peternakan. Sekawanan tikus datang ke Pulau Rona entah dari mana dan memakan semua bijibijian di pulau itu, seperti lebah di wajah yang menangis, ada pelaut yang mendarat lalu mencuri satu-satunya sapi dan membawanya pergi, tidak sampai setahun sejak kejadian itu seluruh penduduk di pulau itu mati karena tidak ada makanan sama sekali.'

Pada konteks kalimat data 5 menceritakan di mana penduduk Pulau Rona yang mendapat kemalangan terus-menerus. Awalnya pulau mereka diserbu oleh tikus yang entah datang dari mana. Sekawan tikus tersebut memakan biji-bijian yang ada di Pulau Rona, seperti kutipan kotowaza 泣き 面に蜂 naki tsurani hachi 'seperti lebah di wajah yang menangis', yang berarti kemalangan yang bertubi-tubi. Penduk Pulau Rona kemudian mendapat kemalangan lagi dengan kedatangan para pelaut ke pulau tersebut dan mencuri sapi milik penduduk Pulau Rona, lalu setahun sejak kejadian tersebut, penduduk di pulau itu mati karena tidak ada makanan sama sekali. Lebah yang berada di wajah yang menangis merupakan kesialan karena sudah menangis kemudian disengat lebah. Kemalangan yang beruntun disini merujuk pada kesialan yang bertubi-tubi yaitu karena serangan tikus, pencurian sapi oleh pelaut, serta penduduk Pulau Rona yang meninggal karena kelaparan. 


\section{Data 6}

犬は三日飼えば三年恩を忘れない

Inu wa mikka kaeba sannen on o wasurenai

Pada data 6 memiliki makna leksikal 'Jika memelihara anjing tiga hari, anjing tersebut tidak akan melupakan berkah yang diterimanya selama tiga tahun', sedangkan makna idiomatikalnya 'membalas budi kebaikan yang telah diterima'. Berdasarkan metafora konseptual terdapat analogi antara inu (anjing) dengan orang yang tahu balas budi. Seperti kita ketahui, anjing adalah binatang pintar dan dikenal sebagai sahabat manusia. Anjing juga dikenal sebagai binatang setia kepada tuannya dan tahu membalas budi.

Berikut ini terlampir kutipan lengkap isi cerita novel bahasa Jepang, yang memuat kotowaza pada data 6 di atas.

$$
\begin{gathered}
\text { 飼主の人間どもが転居する時、猫はそれに従って新居に落付くことなく、旧家に戻りた } \\
\text { がる。それが空家になっていようと、或は新らしい人間どもが住んでいようと、そんな } \\
\text { ことには頓着なく、旧家に住み続けたがる。だから、三日飼われてその恩を三年忘れな } \\
\text { い大と反対に、猫は三年飼われてその恩を三日にして忘れる。 } \\
\text { (https://www.aozora.gr.jp/cards/000906/files/42517222733.html) }
\end{gathered}
$$

Kainushi no ningen-domo ga tenkyo suru toki, neko wa sore ni shitagatte shinkyo ni ochi tsuku koto naku, kyūka ni modoritagaru. Sore ga akiya ni natte iyou to, aruiwa atarashii ningen-domo ga sunde iyou to, son'na kotoni wa tonchaku naku, kyūka ni sumi tsudzuketa garu. Dakara, mikka kawarete sono on o san-nen wasurenai inu to hantai ni, neko wa san-nen kawarete sono on o mikka ni shite wasureru.

'Ketika pemiliknya pindah, kucing tidak ikut pindah ke tempat baru, tetapi ingin kembali ke rumah lama. Entah itu rumah kosong atau ada orang baru yang tinggal di dalamnya, kucing tidak peduli tentang itu dan ingin terus tinggal di rumah lama. Jadi, berbeda dengan anjing yang dipelihara selama tiga hari tetapi tidak akan melupakan kebaikan tersebut selama tiga tahun, sebaliknya, kucing dipelihara selama tiga tahun tetapi akan melupakan kebaikan tersebut dalam tiga hari.'

Pada konteks kalimat data 6, disebutkan bahwa kucing peliharaan yang sudah lama dipelihara kemudian pemiliknya pindah rumah, si kucing tidak ingin ikut. Kucing merasa lebih nyaman tinggal di rumah lama meskipun rumah tersebut akhirnya diisi oleh keluarga lain atau mungkin ditinggalkan kosong. Kucing juga akan dengan mudah melupakan kebaikan pemiliknya yang sudah merawatnya sedari lama karena kucing lebih memilih tempat tinggal yang sudah membuatnya nyaman. Hal ini berbanding terbalik dengan kotowaza 犬は三日飼えば三年恩を忘れない inu wa mikka kaeba sannen on o wasurenai 'Jika memelihara anjing tiga hari, anjing tersebut tidak akan melupakan kebaikan yang diterimanya selama tiga tahun'. Perumpamaan dalam cerita tersebut, 犬 inu 'anjing' yang dipelihara walaupun hanya tiga hari disebutkan akan mengingat kebaikan tuannya dan setia terhadap tuannya, sedangkan 猫 neko 'kucing' akan dengan mudah melupakan kebaikan tuannya. Sehingga dengan kata lain, diharapkan setiap orang tahu membalas budi seperti karakter hewan anjing yang melambangkan kesetiaan.

\subsection{Relevansi Kotowaza Bahasa Jepang yang Mengandung Unsur Hewan dengan Nilai Sosial Budaya Jepang}

Berdasarkan hasil analisis data yang telah dilakukan, diketahui ada keterkaitan erat antara kotowaza bahasa Jepang dan nilai-nilai sosial-budaya dari masyarakat Jepang, di antaranya tersaji pada bagian berikut ini. 


\subsubsection{Relevansi dengan Nilai Sosial "Usaha Keras dan Pantang Menyerah"}

Dikenal sebagai negara yang memiliki semangat tinggi serta sifat kesungguhan dalam bekerja, melahirkan masyarakat Jepang yang disiplin tinggi serta etos kerja untuk selalu maju (Trahutami, 2015, p. 67). Nilai sosial budaya kerja keras menjadi factor penting kesuksesan bangsa Jepang dalam bidang ekonomi, industri, dan perdagangan. Sumber daya alam (SDA) yang tidak begitu melimpah di Jepang disadari oleh bangsanya sehingga memicu semangat untuk meningkatkan sumber daya manusianya agar bisa tetap bersaing dengan negara-negara maju di dunia. Budaya kerjas keras inilah yang menjadikan faktor penting masyarakat Jepang dapat meraih kesuksesan dalam perekonomian dan perdagangan (Seng, 2007, p. 11).

Nilai sosial budaya kerja keras dan pantang menyerah yang muncul dalam kotowaza bahasa Jepang yang mengandung unsur hewan ditunjukkan pada data kotowaza yang berbunyi 鯉の滝登り koi no taki nobori 'ikan koi yang mendaki air terjun' dan 猿も木から落ちる saru mo ki kara ochiru 'monyet pun bisa jatuh dari pohon'. Dalam budaya Jepang, pada perayaan festival anak-anak (sichi go san) akan dikibarkan banyak bendera yang berbentuk ikan koi. Ikan koi dianggap sebagai hewan yang memiliki vitalitas yang bagus di antara ikan lainnya terlihat dari kebiasaannya yang sering melawan arus untuk mencari makan. Jadi diharapkan pada perayaan festival di Jepang, anak-anak akan tumbuh menjadi manusia yang sehat, sukses dan panjang umur layaknya ikan koi yang bekerja keras melawan arus.

\subsubsection{Relevansi dengan Nilai Sosial "Membalas Budi"}

Membalas budi adalah salah satu bentuk dari budaya giri ninjou ciri khas orang Jepang (Trahutami, 2015, p. 68). Dimana giri adalah konsep ajaran 'berhutang budi' yang muncul dari tradisi masyarakat petani pedesaan di Jepang. Sedangkan ninjou berarti tenggang rasa, kasih sayang, serta kebaikan hati yang sudah menjadi kodrat manusia. Konsep ini melahirkan kewajiban moral dalam etika sosial masyarakat Jepang berupa balas budi.

Nilai sosial budaya membalas budi yang tercermin dalam kotowaza bahasa Jepang yang mengandung unsur hewan yaitu 犬は三日飼えば三年恩を忘れない inu wa mikka kaeba sannen on wo wasurenai 'anjing yang dipelihara selama tiga hari dan tidak akan melupakan kebaikan tuannya bahkan hingga tiga tahun kedepan'. Maka begitu pun dengan orang, ketika seseorang memberi bantuan saat diperlukan sudah sepatutnya yang diberi bantuan sadar diri dan membalas kebaikannya dikemudian hari jika orang tersebut membutuhkan bantuannya.

\subsubsection{Relevansi dengan Nilai Sosial "Sikap Bertanggung Jawab dan Malu"}

Budaya kerja keras Jepang menuntut tanggung jawab yang tinggi pada masyarakat pekerjanya. Jadi seluruh tenaga dan komitmen mereka dicurahkan untuk kemajuan perusahaan mereka. Budaya ganbaru dalam masyarakat Jepang memupuk semangat dalam mengerjakan suatu hal utamanya dalam pekerjaan mereka, sehingga sifat tanggung jawab pun muncul bersamaan dengan semangat tersebut. Mereka memberikan segala tenaga untuk kemajuan perusahaan tempat mereka bekerja sebagai bentuk tanggung jawab dan komitmen pada perusahaan (Seng, 2007, p. 188).

Nilai sosial budaya yang muncul dalam data kotowaza bahasa Jepang yaitu 猫をかぶっているneko wo kabutte iru, yang berarti pemalu. Bangsa Jepang lebih memilih bunuh diri atau mati daripada harus menanggung malu karena kekalahan dan kegagalan. Jepang terkenal dengan budaya malunya yang tinggi, hal ini terlihat dari adanya budaya harakiri atau seppuku di Jepang pada zaman dulu. Sejak zaman dulu seorang samurai yang merasa gagal menjalankan tugasnya atau untuk menebus rasa malu keluarganya akan melakukan harakiri atau seppuku. Menggunakan katana, samurai akan membunuh dirinya sendiri dengan merobek isi perutnya hingga keluar. Mereka lebih memilih mati 
Mafrukha, S., Firmansyah, D.B., Stovia, A., (2021). Animal Elements on Japanese Kotowaza and the Implementation of Japanese Socio-Cultural Values: A Cognitive Linguistics Point of View. Japanese Research on Linguistics, Literature, and Culture 3 (2), 141-156. https://doi.org/10.33633/jr.v3i2.4599

dan bunuh diri daripada harus menanggung malu karena tidak dapat mempertanggungjawabkan perbuatannya (Seng, 2007, p. 8).

\subsubsection{Relevansi dengan Nilai Sosial Berupa "Sikap Fokus dan Teliti"}

Bangsa Jepang yang sudah memupuk sikap bertanggungjawab dalam melaksanakan pekerjaannya tentu akan fokus dan teliti agar tujuan atau tugas yang dikerjakannya dapat segera selesai dan mendapat hasil yang maksimal. Sikap lain orang Jepang yang biasanya muncul dalam sosial budaya mereka adalah sikap teliti. Orang Jepang memiliki sifat teliti dalam mengerjakan suatu pekerjaan dan tidak suka terburu-buru tanpa terstruktur. Sebelum mengambil keputusan dan bertindak, orang Jepang memiliki sikap teliti serta cermat (Seng, 2007, p. 64). Bahkan ketika tidak diawasi pun mereka akan tetap fokus dan tidak malas mengerjakan pekerjaan mereka (Seng, 2007, p. 70).

Nilai sosial budaya sikap fokus dan teliti ini tercermin dalam data kotowaza bahasa Jepang yaitu 角を矯めて牛を殺す tsuno wo tamete ushi wo korosu 'memperbaiki tanduk sapi, sama dengan membunuh sapi'. Di mana kotowaza tersebut merupakan pepatah yang mengingatkan supaya jangan sampai ingin memperbaiki masalah kecil namun malah merusak segalanya. Sehingga sebelum bertindak melakukan suatu hal ada baiknya untuk fokus dan teliti memikirkan terlebih dahulu dampak buruk yang akan menyebabkan kerugian.

\subsubsection{Relevansi dengan Nilai Sosial "Kewaspadaan Hidup"}

Kewaspadaan yang dimaksud meliputi kehati-hatian dalam berbicara, bertindak, instrospeksi diri, tidak sombong, serta tidak melakukan perbuatan ceroboh yang dapat merugikan diri sendiri dan orang lain. Orang Jepang terbiasa tanggap dan cekatan dalam menghadapi berbagai tantangan dan ancaman dalam kehidupannya (Trahutami, 2015, p. 69).

Nilai sosial budaya yang tercermin dalam kotowaza bahasa Jepang yang mengandung unsur hewan yaitu 頭の黒いネズミ atama no kuroi nezumi 'tikus berkepala hitam' yang berarti pencuri, 杯 中の蛇影 haichuu no daei 'bayangan ular di dalam cangkir'. Dalam hidup penting untuk selalu mewaspadai keadaan sekitar bahkan terhadap orang-orang di sekitar diri sendiri terkadang perlu diwaspadai. Namun, terkadang sikap waspada yang berlebihan dapat memunculkan sifat curiga yang berlebihan terhadap orang lain. Oleh karena itu, perlu juga untuk membatasi diri karena sesuatu yang berlebihan pun bukanlah sesuatu yang baik.

\section{Simpulan}

Kotowaza adalah produk bahasa dari budaya Jepang yang pada umumnya merupakan nasihat kebaikan yang bertujuan untuk dijadikan pedoman kehidupan. Dari tulisan ini, telah dianalis kotowaza yang berunsur hewan dan pemaknaannya berdasarkan teori metafora konseptual. Terdapat enam jenis hewan, yaitu tikus, kuda, lebah, bangau, ayam, dan anjing. Dari hasil analisis metafora konseptual diketahui bahwa bagi orang Jepang tikus adalah binatang jahat sehingga menjadi domain sumber dari domain target penjahat atau pencuri karena adanya kesamaan sifat yang suka merusak atau mencuri. Kemudian hewan kuda menjadi domain sumber dari kerja keras; lebah dari sesuatu atau seseorang yang ditakuti; bangau adalah seseorang/sesuatu yang bernilai, sementara ayam adalah sesuatu atau seseorang yang biasa saja, dan hewan anjing adalah domain sumber dari domain target orang yang tahu membalas budi.

Dari hasil analisis, juga ditemukan terdapat 5 (lima) relevansi nilai sosial budaya masyarakat Jepang yang tercermin dalam kotowaza bahasa Jepang yang mengandung unsur hewan, yaitu usaha keras dan pantang menyerah, membalas budi, kewaspadaan hidup, sikap bertanggungjawab dan malu, serta sikap fokus dan teliti. 
Mafrukha, S., Firmansyah, D.B., Stovia, A., (2021). Animal Elements on Japanese Kotowaza and the Implementation of Japanese Socio-Cultural Values: A Cognitive Linguistics Point of View. Japanese Research on Linguistics, Literature, and Culture 3 (2), 141-156. https://doi.org/10.33633/jr.v3i2.4599

\section{Referensi}

Arimi, S. (2005). Contested Wisdom in Indonesian and Japanese Proverbs. Studies in Urban Cultures, 6, 76-101.

Chaer, A. (2009). Pengantar Semantik Bahasa Indonesia. Jakarta: Rineka Cipta.

Cuykens, H., \& Zawada, B. (2001). Polysemy in Cognitive Linguistics. Amsterdam: John Benjamins Publishing.

Geeraerts, D. (2006). Cognitive Linguistics: Basic Readings. Berlin: Morton de Gruyter.

Ghassani, N. S., \& Saifudin, A. (2020). Studi Metafora Konseptual pada Idiom Bahasa Jepang yang mengandung Bagian Tubuh dan Bermakna Emosi. Japanese Research on Linguistics, Literature, and Culture, 2(2), 161-177. doi:https://doi.org/10.33633/jr.v2i2.3990

Hadi, L. (2018). Kajian Makna dan Nilai Budaya Peribahasa Jepang dan Indonesia Menggunakan Elemen Nama Hewan. HIKARI , 6 (2) , 1-9.

Hanindar, M., \& Andini, R. (2017). Analisis Makna Kotowaza yang Terbentuk dari Kata Anjing (犬) serta Padanannya dalam Peribahasa Bahasa Indonesia. Journal Japanology, Volume 5 (2), 146157.

Kharina, M., \& Sudjianto. (2016). Analisis Kotowaza yang Terkait dengan Kanji Musim dan Relevansinya dengan Kebudayaan Jepang. Japanedu, 1 (1).

Lakoff, G., \& Johnson, M. (1980). Metaphors We live by. London: The University of Chicago Press.

Momiyama, Y. (2010). Ninchi gengogaku Nyūmon (Introduction to cognitive linguistics). Tokyo: Kenkyūsha.

Nisa. (2018). Linguistik Kognitif dalam Majas Metafora, Metonimi dan Sinekdoke Bahasa Jepang. Jurnal Diglossia, 10 (1), 25-30.

Saifudin, A. (2018). Konseptualisasi Citra Hara 'Perut' dalam Idiom Bahasa Jepang. Japanese Research on Linguistics, Literature, and Culture, 1(1), 65-78. doi:https://doi.org/10.33633/jr.v1i1.2130

Santoso, T., \& Riani, R. (2019). Makna Metafora Idiom (Kanyouku) dalam Unsur Mata (Me): Sebuah Kajian Linguistik Kognitif. Journal of Japanese Language Education \& Linguistics, Volume 3 (1), 35-55.

Sekarsari, W., \& Haristiani, N. (2016). Analisis Makna Kanyouku yang Berkaitan dengan Warna: Kajian Linguistik Kognitif. Jurnal Pendidikan Bahasa dan Sastra, 16 (1), 96-109.

Seng, A. W. (2007). Rahasia Bisnis Orang Jepang Terj. Widyawati O. Senmon Kyouiku Publishing.

Shinmura, I. (1973). Koujien. Tokyo: Iwanami Shouten. 
Mafrukha, S., Firmansyah, D.B., Stovia, A., (2021). Animal Elements on Japanese Kotowaza and the Implementation of Japanese Socio-Cultural Values: A Cognitive Linguistics Point of View. Japanese Research on Linguistics, Literature, and Culture 3 (2), 141-156. https://doi.org/10.33633/jr.v3i2.4599

Sudaryanto. (2015). Metode dan Aneka Teknik Analisis Bahasa. Yogyakarta: Sanata Dharma University Press.

Sugiyono. (2013). Metode Penelitian Kuantitatif, Kualitatif dan R\&D. Bandung: Alfabeta.

Swasono, R. N., \& Saifudin, A. (2013). Makna Idiom Hana dalam Perspektif Budaya Orang Jepang. Prosiding Asosiasi Studi Jepang di Indonesia, (pp. 1-15).

Trahutami. (2015). Nilai Sosial Budaya Jepang dalam Peribahasa Jepang yang Menggunakan Konsep Binatang. Jurnal Izumi, 64-71.

Yohani, A. M. (2015). Kotowaza dalam Kajian Linguistik Kognitif: Penerapan Gaya Bahasa Metafora. Seminar Nasional: Strategi Indonesia Kreatif. 8 (1), pp. 89-98. Bandung: Universitas Widyatama. 